A SPECIAL ISSUE FOR THE $6^{\text {TH }}$ SCIENTIFIC INTERNATIONAL CONFERENCE

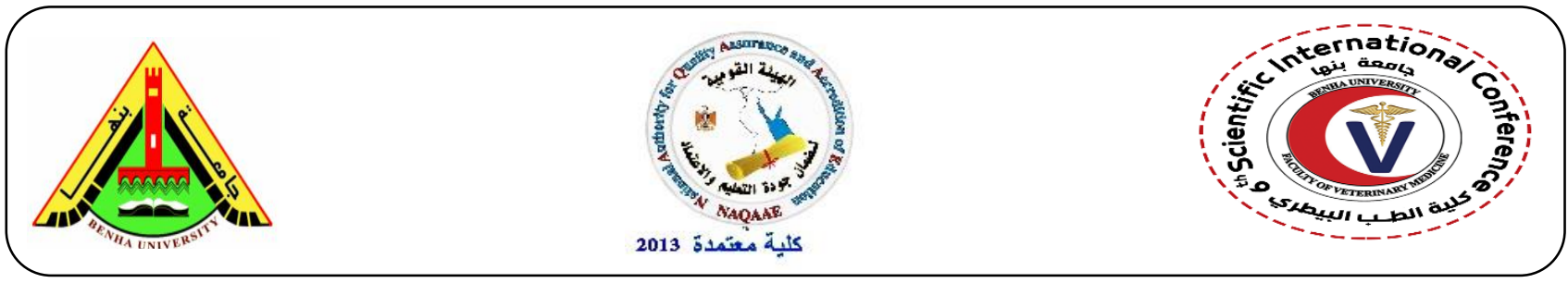

\title{
Biochemical Role of Folic Acid Loaded Magnetic Nanoparticles Versus Gamma Irradiation in Rats
}

\author{
Samy Ali Hussein'1., Abdelmaksoud H¹., Saleh H. M²., Hassanin W.F. ${ }^{2}$, Eman. I. Sobeh ${ }^{2}$ \\ ${ }^{1}$ Department of Biochemistry and clinical Biochemistry, Faculty of Veterinary Medicine, Benha \\ University. \\ ${ }^{2}$ Department of Biological Applications, Nuclear Research Center, Atomic Energy Authority, Egypt.
}

\section{A B S T R A C T}

Gamma radiation produces numerous biological perturbations in cells by direct ionization of DNA and cellular targets and by indirect effect through damage by free radical production. The present study has been carried out to investigate the possible therapeutic effect of folic acid loaded magnetic nanoparticles through injection after body gamma irradiation of rats. We have shown that the folic acid loaded magnetic nanoparticles administration reduced the risk factors induced by $\gamma$ radiation. 60 male albino rats of about 130-150 g live body weight were divided into six groups, Negative control $(n=10)$, Magnetic control $(n=10)$, folic acid loaded Magnetic NPs control $(n=10)$, and 6 Gy irradiation group $(n=10)$. Three post irradiation groups where these groups exposed firstly to 6 Gy gamma irradiation then injected (I.p) by magnetite NPs, and folic acid loaded magnetic NPs, twice weekly for three weeks. The rats in all groups were anaesthetized, decapitated, the liver was excised immediately, and frozen at -80 0c. DNA damage in rat hepatocytes were determined by comet assay, and determined cholesterol and triglyceride concentration. Results showed that whole body gamma irradiation of rats at 6Gy (single dose) induced significant increase in DNA damage ( $\mathrm{P}$ $<0.05)$ that was indicated by increase in tail length, tail DNA\% and tail moment as compared to control group. And significant increase in the hepatic cholesterol and triglycerides levels was observed after three weeks post-irradiation Administration of folic acid loaded magnetic iron oxide (Fe3O4) after irradiation induced significant improvement of the DNA damage and hepatic cholesterol and triglyceride level. These results indicate the role of folic acid loaded MNPs as a radio protector agent. Further, we also report the radio protective property of folic acid loaded MNPs as demonstrated by reduction in the radiation induced DNA damage, which was measured by alkaline comet assay.

Key words: Folic acid loaded magnetic nanoparticles, radio protector, cholesterol, triglyceride and DNA damage by comet assay. 


\section{INTRODUCTION}

required for normal metabolism and regulation (Kesavan et al., 2003). Some reports suggest that folate can acts as a radical scavenger, there by contributing to protection against $\gamma$ ray induced chromosomal damage (Joshi et al., 2001 and Endoh et al., 2006). It has been reported that the radical scavenging of folate is equivalent to that of vitamin C. Endoh et al., 2006 suggested that folate could prevent radiation-induced DNA damage by the modification of DNA synthesis and /or repair and as a radical scavenger that traps oxygen radicals produced by radiation. The aim of the present study is to investigate the effect of vivo supplementation with folic acid loaded magnetic NP against DNA damage, triglyceride and cholesterol induced by ionizing radiation.

\section{MATERIALS AND METHODS}

\subsection{Materials}

\section{1.a. Animals}

Adult male albino rats of pure strain ranging from 130-150g body weight were obtained from the animal house of the Animal Nutration research unit in the National center for radiation research, Egyptain Atomic Energy Authority. Animals were housed in especially designed cages (5 rats/ cage). All rats were kept under good condations, allowed free access to tap water and pellet diet.

\section{1.b. Irradiation}

Whole body irradiation was performed by Gamma- cell 40 (cesium- 137) source belonging to NCRRT. Animal were irradiation $6 \mathrm{~Gy}$ as a single dose, by dose rate of 0.957 $\mathrm{Rad} / \mathrm{s}$.

\section{1. c. Experimental design}

Ionizing radiation is known to produce oxidative stress through the generation of ROS leading to a variety of DNA lesions which consequently leads to lethal effects, Mutagenesis, genomic instability or carcinogenesis (El Suhaibani, 2009). Efforts has been made during recent years to identify phytochemical or other naturally occurring compounds which can reduce the harmful effect of radiation during accidental exposure or prevent normal tissue injury during radiotherapy (Nair and Menon, 2013). Because of their very small size, Nanoparticles (NPs) can be more chemically reactive, and likely have much greater access into cells, tissues, and organs than larger particles. The important technological advantages of nanoparticles used as drug carries are high stability, high carrier capacity, feasibility of incorporation of both hydrophilic and hydrophobic substances, and feasibility of variable routes of administration. NPs, because of their distinct properties compared to the bulk form of the same material, are thus subject to many studies on developments in the fields of biosensors, biomedicine, and bio nanotechnology (Hanaa et al., 2014). Iron oxide nanoparticles (NPs) have been the most extensively investigated, due to their excellent biocompatibility and ease of synthesis for multifunctional biomedical applications such as cellular targeting and drug delivery, tissue repair, magnetic resonance imaging (MRI) and magnetofection (Bhasskar et al., 2010).

Folic acid (FA) is an essential B vitamin, obtained through dietary sources, such as broccoli, cabbage, fruit and nuts. Folic acid is playing an essential role in nucleic acid synthesis, methionine regeneration, and in Various one-carbon unit reactions 


\section{2.a.Chemicals:-}

Iron (II) chloride tetrahydrate $\left(\mathrm{FeCl}_{2}-\right.$ $\left.4 \mathrm{H}_{2} \mathrm{O}\right)$, iron (III) chloride hexahydrate $\left(\mathrm{FeCl}_{3}-\right.$ $6 \mathrm{H}_{2} \mathrm{O}$ ), polyethylene Glycol 6000, Folic acid, Dimethylsulfoxide, and dicyclohexyl carbodiimide were purchased from SigmaAldrich, were purchased from Sigma-Aldrich (USA). Ammonium hydroxide solution $\left(\mathrm{NH}_{4} \mathrm{OH}\right)$ was obtained from Merck (Germany).

\subsection{Methods:-}

\section{1.a. Preparation}

Iron oxide $\left(\mathrm{Fe}_{3} \mathrm{O}_{4}\right)$ nanoparticles were synthesized via a co precipitation process of $\mathrm{Fe}(\mathrm{III})$ and $\mathrm{Fe}(\mathrm{II})$ salts at 2:1 ratio with ammonium hydroxide reported previously (Yallapu et al., 2010) with minor modifications. Briefly, $\mathrm{FeCl}_{3} \cdot 6 \mathrm{H}_{2} \mathrm{O}(11.60 \mathrm{~g})$ and $\mathrm{FeCl}_{2}-4 \mathrm{H}_{2} \mathrm{O}(4.30 \mathrm{~g})$ were dissolved in $400 \mathrm{~mL}$ of deionized water within a fivenecked glass balloon under nitrogen gas protection with vigorous stirring at $85^{\circ} \mathrm{C}$. Subsequently, about $20 \mathrm{~mL}$ of ammonium hydroxide solution was added to the solution and stirring was continued till black precipitate was formed. The precipitate was then washed twice with distilled water.

\section{1.b. Modification of MNPs with folic acid: -}

Folic acid needs the activation of its carboxyl group with dicyclohexyl carbodiimide (DCC) on conjugate to surface of MNPs (Zhang et al., 2008). Folic acid and DCC with 1:1 ratio were added in dimethylsulfoxide (DMSO) and stirred for $2 \mathrm{~h}$. PEG-MNPs sample was added and continuously stirred for $2 \mathrm{~h}$. Then washing of the nanoparticles with $\mathrm{H}_{2} \mathrm{O}$.

\section{1.c Characterization :-}

The characterization of synthesized nanoparticles was performed by transmission
Animal were divided into six groups(10 rats each):-

control group (con): Non- irradiated normal control rats and administered with distilled water.

MNPs group: - Consists of non-irradiated rats that are treated with magnetic iron oxide $\mathrm{Fe}_{3} \mathrm{O}_{4}$ nanoparticles. This group used to study the effect of magnetic iron oxide nanoparticles alone on normal (non-irradiated) rats. Each rat received dose from magnetic iron oxide nanoparticles $(1.5 \mathrm{mg} / \mathrm{kg}$ ) (Eman et al, 2014) in distilled water according its weight for three weeks.

Folic acid -MNPs group: - Consists of nonirradiated rats that are treated with Folic acid loaded magnetic iron oxide $\mathrm{Fe}_{3} \mathrm{O}_{4}$ nanoparticles. This group used to study the effect of Folic acid loaded magnetic iron oxide nanoparticles alone on normal (non-irradiated) rats. Each rat received dose from Folic acid loaded magnetic iron oxide nanoparticles $(1.5 \mathrm{mg} / \mathrm{kg})$ (Eman et al, 2014) in distilled water according its weight for three weeks.

Irradiated group: - (Gamma irradiated) Rats (whole body) were exposed to a single dose of 6 Gy gamma irradiation. This group used to study the effect of gamma irradiation alone on normal rats.

Irradiated MNPs group:- Rats were first exposed to whole body gamma radiation as a single dose $6 \mathrm{~Gy}$ and then injected intraperitoneally with iron oxide $\mathrm{Fe}_{3} \mathrm{O}_{4}$ $(1.5 \mathrm{mg} / \mathrm{kg})$ twice a week for three successive weeks.

Irradiated Folic acid- MNPs group:- Rats were first exposed to whole body gamma radiation as a single dose 6Gy and then injected intraperitoneally with Folic acid loaded iron oxide $\mathrm{Fe}_{3} \mathrm{O}_{4}(1.5 \mathrm{mg} / \mathrm{kg})$ twice a week for three successive weeks. 
of DNA from immobilized nuclear DNA (Singh et. al, 1988). Advantages of the comet assay for assessing DNA damage includes: (1) damage to the DNA in individual cells is measured; (2) only small number of cells are needed to carry out the assay $(<10,000)$; (3) the assay can be performed on virtually any eukaryotic cell type; (4) and it is faster and more sensitive than the alkaline elution method for detecting DNA damage.

\section{1.g. Statistical analysis:-}

All results were expressed as the mean \pm SD. Statistical analysis was performed using statistical package for the social science for windows (Spss, version 11.0, Chicago, IL, USA). The data were analysed by one-way analysis of variance (ANOVA).

\section{RESULTS}

3.1.Transmission electron microscopy. The micro-structural features of the MNPs-Folic acid were studied using TEM.

Shapes and size of MNPs-Folic acid were analyzed by TEM In Fig. (1), shape and morphology of MNPs-Folic acid are seen regular and spherical. Their sizes were between 10-20 $\mathrm{nm}$ approximately. electron microscopy (TEM), and Fourier transform- infrared spectroscopy (FT-IR).

\section{1.d. Sampling:-}

Blood samples were taken from the retroorbital venous plexus under light ether aneathesia .Each blood sample was collected into tubes without anticoagulant for separation of serum for determination of serum cholestrol and triglyceride. Animals in all groups were sacrificed by decapitation and liver was excised, then perfused with cold saline to exclude the blood cells and then blotted on filter paper, and stored at $-20^{\circ} \mathrm{C}$ for subsequent DNA damage by comet assay.

3.1.e. Determination of serum cholesterol and triglyceride

Cholesterol and triglyceride were determined enzymatically with commercial Kit from bio diagnostic. Serum triglyceride and cholesterol were determined enzymatically according to the Fassati and Percipe (1982).

\section{1.f. comet assay:-}

Comet assay (also called, single cell gel electrophoresis, SCGE) was used to detect any prospective damage for DNA after various treatments. It detects DNA strand breaks and alkali labile sites by measuring the migration 

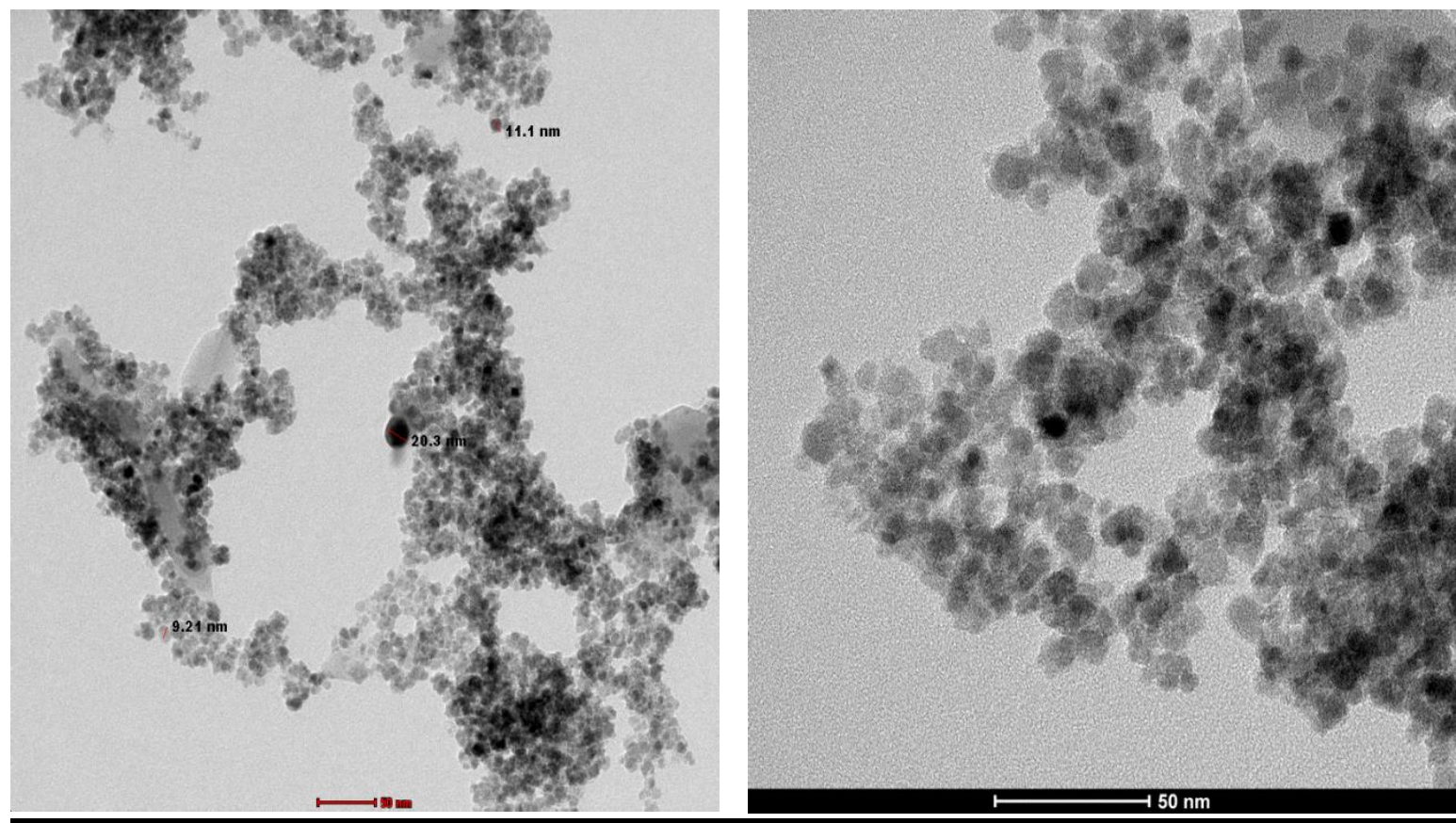

Fig (1) TEM image of Folic acid loaded $\mathrm{Fe}_{3} \mathrm{O}_{4}$ magnetic nanostructures

primary amine in molecules. Absorption at 1609 $\mathrm{cm}^{-1}$ corresponded to aromatic ring stertching vibration in the folic acid molecule, absorption at $1396 \mathrm{~cm}^{-1}$ corresponded to the benzoic vibrations in folic acid molecule, and absorption at $1533 \mathrm{~cm}^{-1}$ can be attributed to the characteristic absorption of amide. Infrared data proved that folic acid molecules have successfully modified the surface of $\mathrm{Fe}_{3} \mathrm{O}_{4}$ nanoparticles.
3:2 FTIR. The FTIR spectra of magnetite and folate coated magnetite were obtained as shown in figure (2) for magnetite, the two strong absorption bands at around 633 and $578 \mathrm{~cm}^{-1}$, which corresponds to the Fe-O bond of bulk magnetite. But the surface groups of folic acid modified magnetite was the absorption peaks at 596 and $445 \mathrm{~cm}^{-1}$ are attributed to $\mathrm{Fe}-\mathrm{O}$ bond absorption. The absorption peak at $1643 \mathrm{~cm}^{-1} \mathrm{can}$ be attributed to N-H bending vibration, which is also favorable evidence for the existence of

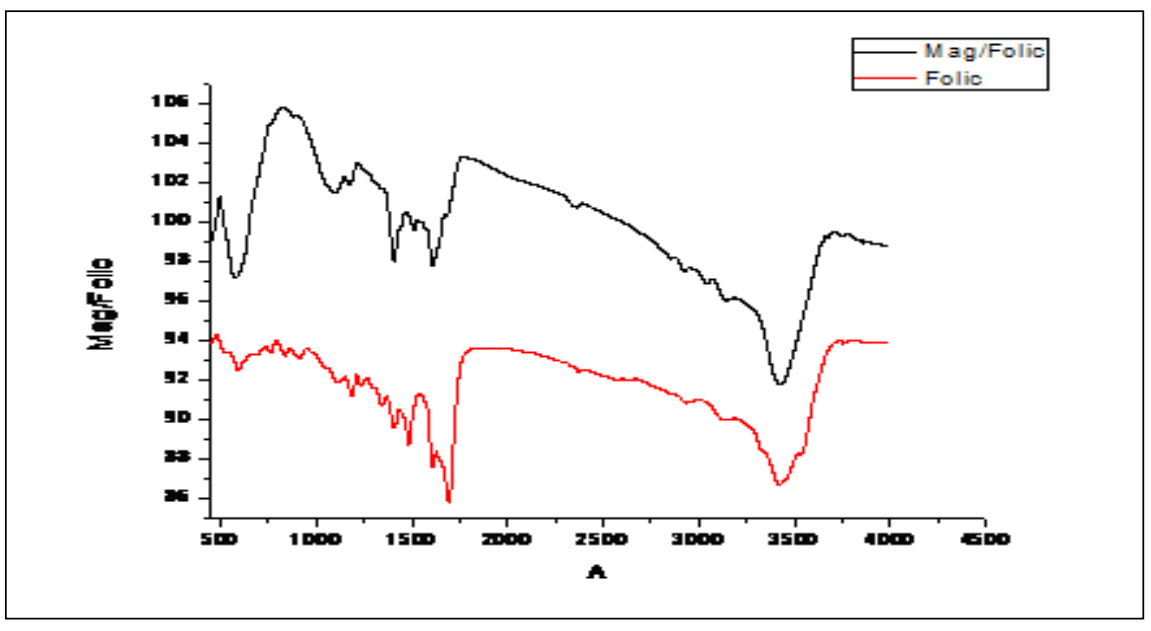

Fig (2): FTIR folic loaded magnetic NPs 
Table (1). The effect of MNPs, MNPs-Folic acid, and gamma-irradiation on serum cholesterol in irradiated rats.

\begin{tabular}{lccc}
\hline \multicolumn{1}{c}{ parameter } & \multicolumn{3}{c}{ Postirradiation } \\
\cline { 2 - 4 } groups & cholestrol \\
Control & The first week & Thesecond week & The third week \\
MNPs & $143.6^{\mathbf{b}} \pm 17.6$ & $146.2^{\mathbf{c}} \pm 15.02$ & $148.9^{\mathbf{c}} \pm 4.48$ \\
MNPS-folic acid & $139.3^{\mathbf{b}} \pm 8.22$ & $138.8^{\mathbf{c}} \pm 1.71$ & $145.02^{\mathbf{c}} \pm 2.33$ \\
irradiation & $123.6^{\mathbf{b}} \pm 4.52$ & $133.9^{\mathbf{c}} \pm 12.8$ & $141.7^{\mathbf{c}} \pm 2.42$ \\
R+ MNPs & $195.1^{\mathbf{a}} \pm 9.04$ & $212.9^{\mathbf{a}} \pm 5.07$ & $225.5^{\mathbf{a}} \pm 10.8$ \\
R+ MNPS-FA & $182^{\mathbf{a}} \pm 5.4$ & $188.3^{\mathbf{a b}} \pm 6.82$ & $182.9^{\mathbf{b}} \pm 10.2$ \\
\hline
\end{tabular}

Means within the same column carrying different superscript letters are significantly different $(\mathrm{P}<0.05)$.

Table (1) showed serum cholesterol concentration in the controls and irradiated animals before and after MNPs- FA supplementation. Serum cholesterol levels in irradiated animals were increased significantly in the first week, the second week, and the third week when compared with control animals. After the administration of MNPs- FA to irradiated animals the enhanced levels of cholesterol were brought back almost to control values.

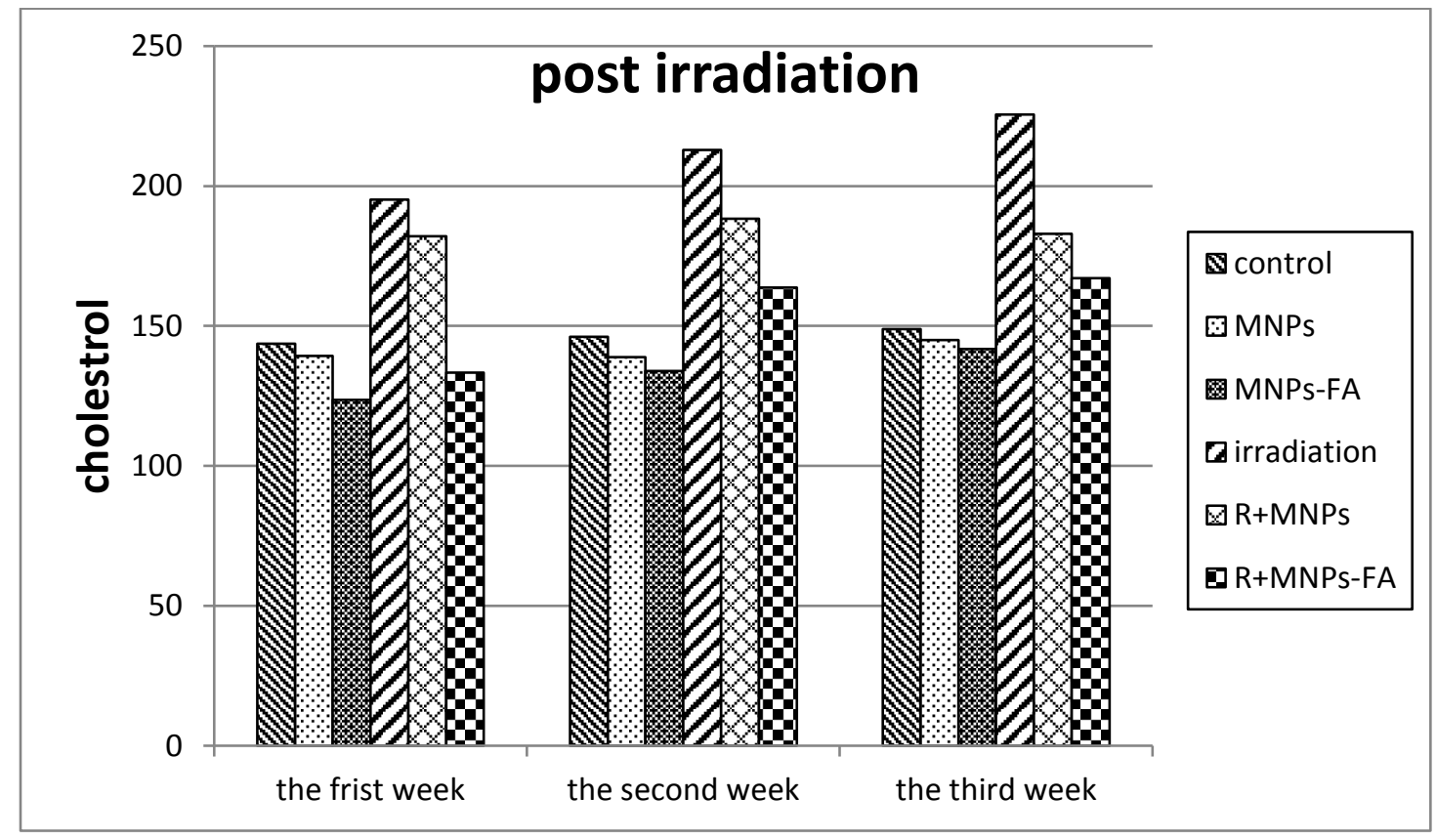

Fig (3) The effect of MNPs, MNPs-folic acid, and $\gamma^{-}$irradiation on seurm cholestrol in irradiated rats. 
Table (2). The effect of MNPs, MNPs-Folic acid, and gamma-irradiation on serum triglyceride in irradiated rats.

\begin{tabular}{lccc}
\hline \multicolumn{1}{c}{ parameter } & \multicolumn{3}{c}{ Postirradiation } \\
\cline { 2 - 4 } & \multicolumn{3}{c}{ Triglyceride } \\
groups & The first week & Thesecond week & The third week \\
control & $83^{\mathrm{b}} \pm 3.4$ & $76.4^{\mathrm{bc}} \pm 2.3$ & $80.1^{\mathrm{bc}} \pm 2.2$ \\
MNPs & $67.3^{\mathrm{c}} \pm 7.02$ & $71.9^{\mathrm{cbd}} \pm 8.0$ & $79.2^{\mathrm{bc}} \pm 7.8$ \\
MNPS-folic acid & $41.7^{\mathrm{d}} \pm 4.5$ & $42.4^{\mathrm{cd}} \pm 5.3$ & $47.2^{\mathrm{cd}} \pm 5.29$ \\
irradiation & $116.5^{\mathrm{a}} \pm 6.22$ & $120.4^{\mathrm{a}} \pm 5.6$ & $123.0^{\mathrm{a}} \pm 5.8$ \\
R+MNPs & $107.5^{\mathrm{a}} \pm 5.91$ & $85.3^{\mathrm{b}} \pm 31.4$ & $89.6^{\mathrm{b}} \pm 30.9$ \\
R+MNPs-FA & $73.6^{\mathrm{bc}} \pm 2.8$ & $49^{\mathrm{cd}} \pm 19.3$ & $54.6^{\mathrm{cd}} \pm 18.8$ \\
\hline
\end{tabular}

Means within the same column carrying different superscript letters are significantly different (P $<0.05)$.

Table (2) showed serum triglyceride levels in controls and irradiated animals before and after MNPs-FA supplementation. TG levels were highly increase significantly in irradiated animals when compared with control animals. Administration of MNPs- folic acid to these animals reduced TG level which is comparable to the control values. However, there were significantly change to best observed after MNPs-FA supplementation of control groups.

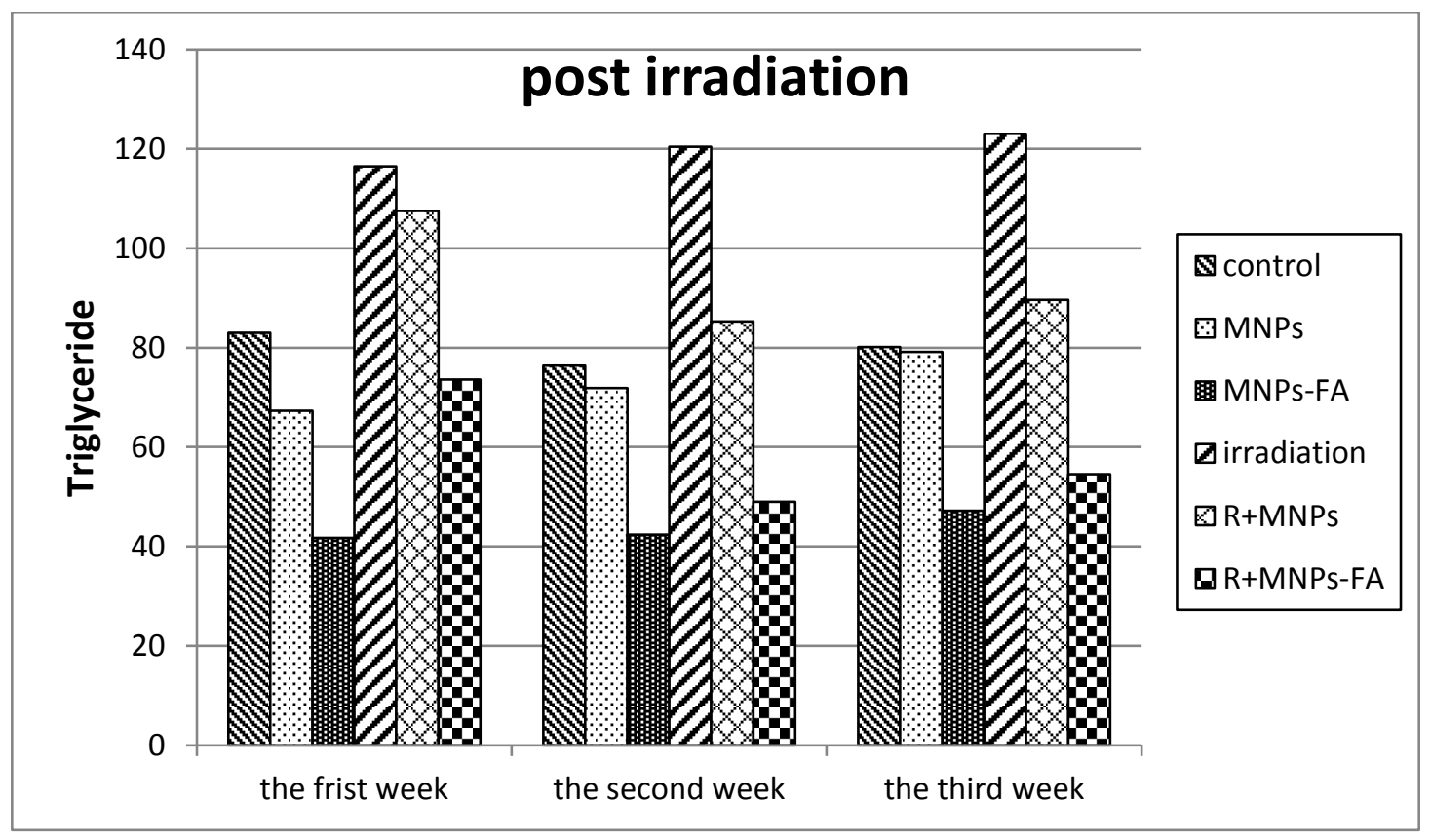

Fig (4) The effect of MNPs, MNPs-folic acid, and $\gamma^{-}$irradiation on seurm cholestrol in irradiated rats. 
Table (3): Comet assay parameters obtained by image analysis in cells of all groups after treatment experiment.

\begin{tabular}{cccccc}
\hline Group & Tailed \% & Untailed $\%$ & Tails length $\mu \mathrm{m}$ & Tail DNA\% & Tail moment \\
\hline control & 2 & 98 & $1.45 \pm 0.12^{\mathrm{d}}$ & 1.54 & 2.23 \\
MNPs & 5 & 95 & $2.03 \pm 0.35^{\mathrm{d}}$ & 1.85 & 3.75 \\
Folic acid & 4 & 96 & $1.85 \pm 0.22^{\mathrm{d}}$ & 1.71 & 3.16 \\
-MNPs & & 71 & $9.42 \pm 0.68^{\mathrm{a}}$ & 8.11 & 76.40 \\
Irradiation & 29 & 84 & $5.72 \pm 0.29^{\mathrm{b}}$ & 4.73 & 27.05 \\
R+MNPs & 16 & & & & \\
\hline R+Folic & & 88 & $4.51 \pm 0.21^{\mathrm{b}, \mathrm{c}}$ & 3.56 & 16.06 \\
acid- & 12 & & & & \\
MNPs & & & & & \\
\hline
\end{tabular}

Different superscript letters in the same column of tail length showed significance difference at $\mathrm{P}<$ 0.05

A comet assay was performed to assess DNA damage in liver of radiation-induced hepatic damage in rats after treatment by magnetic nanoparticles, or MNPs-Folic acid as compared to control. The results of comet assay were shown in Figures and Tables (5 and 3). Exposure to radiation (G4) led to significant increase in DNA damage $(\mathrm{P}<0.05)$ that was indicated by increase in tail length, tail DNA\% and tail moment as compared to control group. This increased DNA damage was reduced after administration of magnetic NPs (G5), Folic loaded magnetic Nps (G6), for 3 weeks. On the other hand, no significant difference in DNA damage (tail length) was observed between normal control (G1) and control treated groups (G2-3).

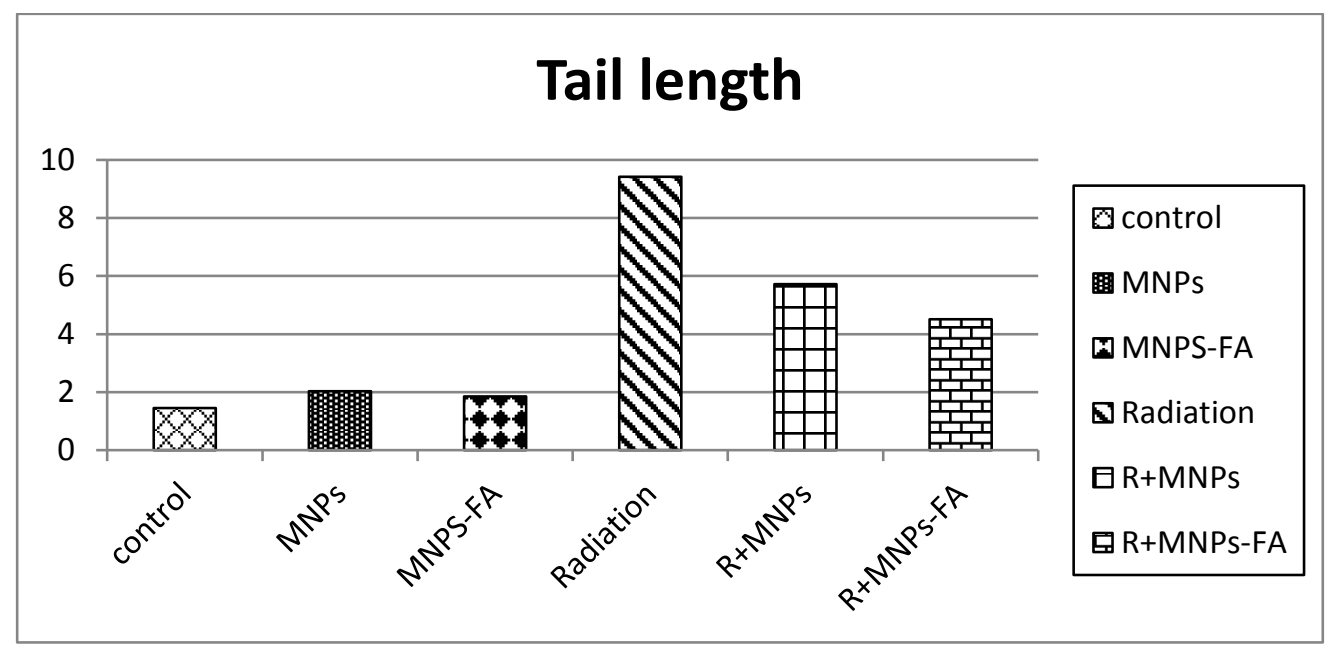

Fig.(5) The effect of MNPs, MNPs-folic acid, and $\gamma^{-}$irradiation on hepatic DNA damage in irradiated rats. 


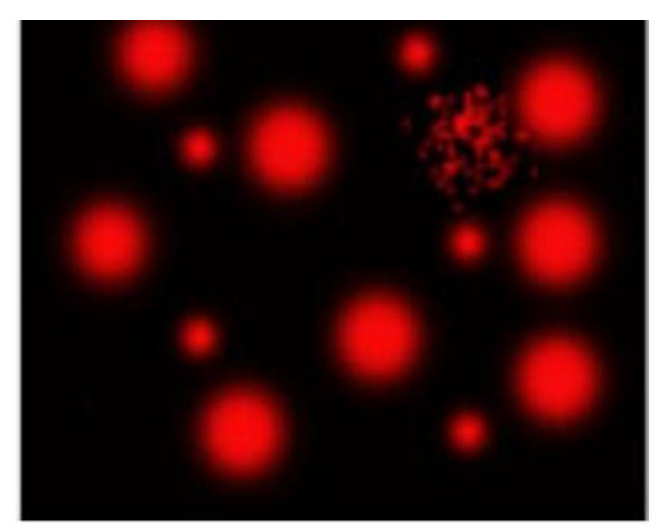

Control group

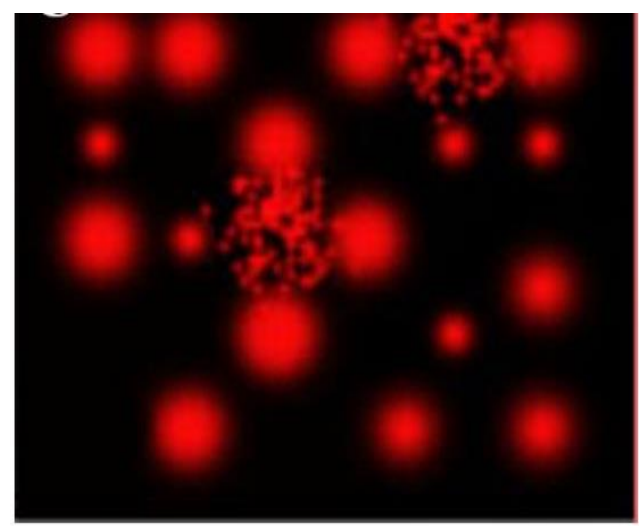

MNPS-Folic acid group

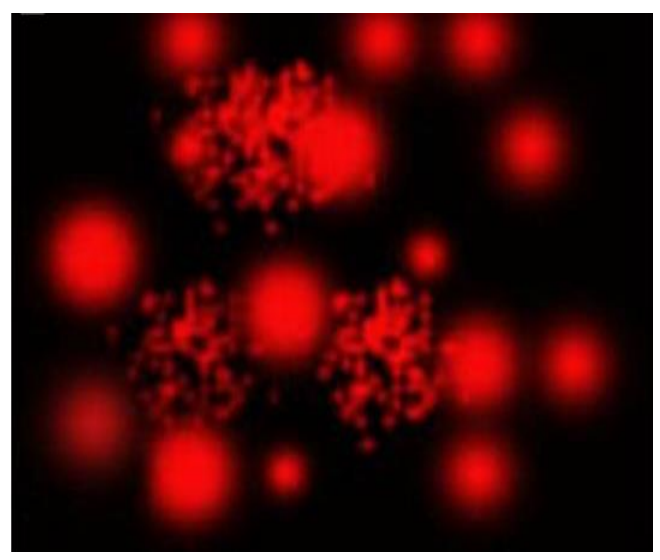

Irradiated MNPs group

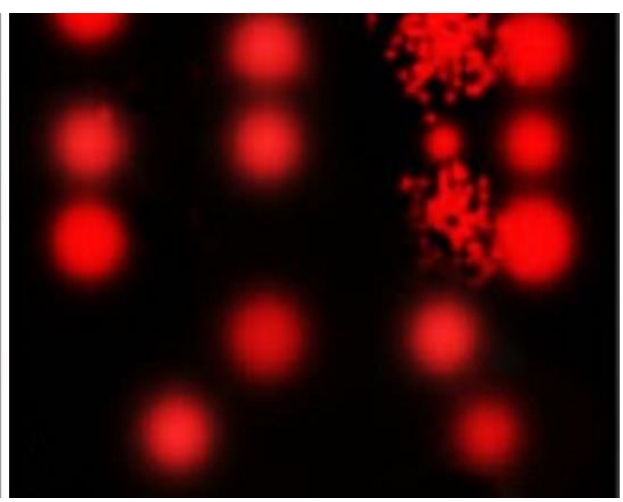

MNPs control group

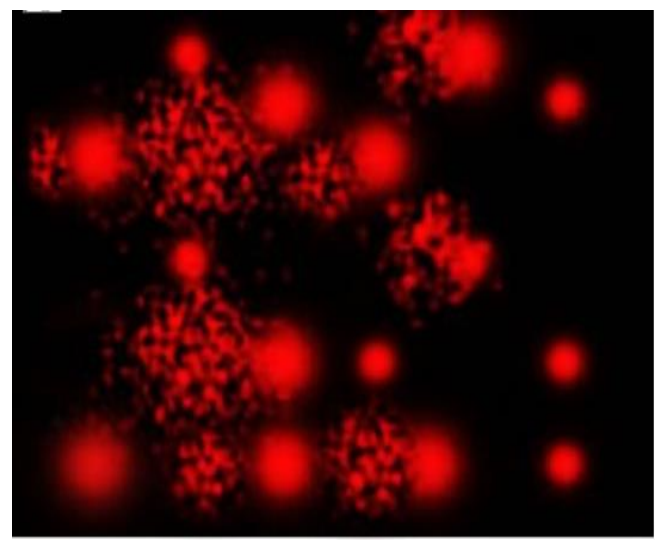

irradiated group

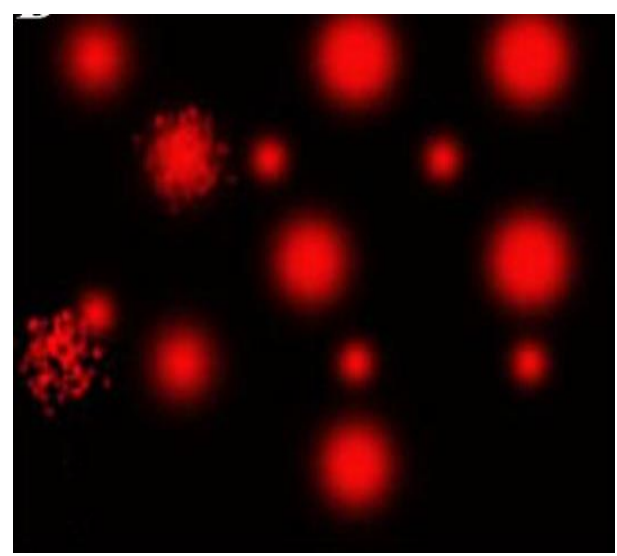

Irradiated MNPs-folic acid group

Fig (6) The effect of MNPs, MNPs-Folic acid, and ${ }_{\gamma}$ - irradiation on hepatic DNA damage in irradiated rats. 


\section{DISCUSSION:}

In the present studies showed the significant increase in the TG levels in irradiated animals. The folate supplemented irradiated animals showed a great reduction in the TG levels. This drop occurred may be due to reduction of plasma lipase activity after folate administration in the irradiated group (Table 2).

In the present study folic acid was observed to have a role as an antiatherogenic agent in reducing the elevated atherogenic parameters (Pote et al., 2006).

There are several factors, which can induce the atherogenic changes in mammalian system. One of them is exposure to ionizing radiation (Chaialo, et al., 2001). Radiation exposure is known to cause the oxidative damage involving reactive oxygen species.

Our results have shown that the $\gamma$-irradiation exposure increased the proatherogenic factors as cholesterol, and triglycerides which may be due to that radiation caused atherogenic changes in these profiles, but FA administration prevented this increase in the lipid profiles (Table 1).

It is widely believed that Folic acid might have acted through its involvement in the methylation of homocysteine to methionine Reports have appeared suggesting that elevated plasma levels of homocysteine have been associated with increased risk of atherosclerosis (McCully KS, Review) Folic acid deficiency is known to prevent conversion of homocysteine to methionine conversion resulting in accumulation of homocysteine (Pote, et al., 2006). The high concentrations of homocysteine are known to injure the endothelium cells, which could lead to atherogenesis (Malinlinow, et al., 2006). It has been suggested that the significance of FA in atherosclerosis could lie in its ability to lower the elevated homocysteine level rather than to any direct association of the vitamin in the etiology of coronary heart disease (Pancharuniti, et al., 1994). The cellular membrane and DNA are the two major targets.

Adequate folate status is vital for cell division and homeostasis because of its essential role in nucleic acid synthesis, methionine regeneration and in various one-carbon units required for normal metabolism and regulation (Londhe et al., 2009). Elevated oxidized folate levels and altered folate homeostasis have also been reported after $\gamma$ irradiation of mice (Batra, et al., 2004). folate coenzyme acts as donors and acceptors of onecarbon units in a variety of reactions involved in one carbon metabolism is essential for DNA synthesis (Batra, et al., 2004).

Radiation stress mediated DNA damage induces several metabolic processes some of which involve facilitation of folate- mediated reactions (Moson, et al., 2000). Folate stores of liver, the central organ involved in one- carbon metabolism. Can be mobilized to meet the requirements of different tissue systems in the body (Baggott, et al., 2003). Total body irradiation may adversely affect supply of this essential vitamin to all the tissues, especially those containing rapidly dividing cells. Rapidly dividing cells are critically dependent on an abundant supply of fully reduced folates, which are essential for formation of nuclotides required for DNA synthesis and repair (Kim, et al., 1996, Yehuda, et al., 2003).

\section{CONCLUSION:}

The present results suggest that folic acid loaded MNPs controlled the excess production of free radicals produced by gamma irradiation and have a protective effect against oxidative stress by decreasing triglyceride and cholesterol concentrations and increasing the antioxidant system. They would protect the liver from oxidative damage and preserve the integrity of tissue functions.

\section{REFERENCES}


Baggott J. E., Mackenzie R.E., (2003): 5, 10Methenyl tetrahydrofolate cyclohydrolase, rat liver and chemically catalyzed formation of 5formyltetrahydrofolate. Biochem. J., (374): 773-778.

Batra V., Vellapan K., Kaushal P., Mishra a., (2004): Modulation of enzymes involved in folate dependent onecarbon metabolism by gamma radiation stress in mice. J. Radiat. Res. (45):527-533.

Bhasskar S., Tian F., Stoeger T., Kreyling W., Fuenteet J. M. de la, Grazu V., Brom P., Estrada G., Ntziachritos V., Razansky D., (2010). Multifunctional nanocarriers for diagnostics, durg delivery and targeted treatment across blood-brain barrier: Perspectives on tracking and neuroimaging. Part fibre Toxicol, (7): 1-3.

Chaialo PP, Pliushch GI., (2001): Pathogenic role of free-radical damage in radiation Induced atherrosclerosis. Fiziol $\mathrm{Zh} \mathrm{47:}$ 107-115.

El Suhaibani S. Entissar. (2009). Protective effect of curcumin on $\gamma$-radiationinduced sister chromatid exchanges in human blood lymphocytes. Int. J.Low Radiat.6, 21-27.

Eman Sobeh, Souad El Feky, Rehab Amin, Eldemeryaty A. S., (2014). Studying the biostimulatory effect of magnetic nanoparticles on irradiated rats. M.S.C. Thesis, cairo univ.

Endoh k, Murakarmi M, Araki R, Maruyama C and Umegaki K. (2006) Low folate status increases chromosomal damage by X-ray irradiation. Int. J. Radiat. Biol, 82-223.
Fossati, Prencipe L., (1982). Serum triglycerides determined colorimetrically with an enzyme that produce hydrogen peroxide. Clin. Chem., (10). 2077-80.

Hanaa Hussein Elsayed, Alsayed A. M. AlSherbini, Eman Elsayed Abd-Elhady, Kawkab Abd El Aziz. Ahmed. (2014). Treatment of Anemia progression via Magnetite and folate nanoparticles in vivo. J. ISRN Nanotechnology.1-13.

Joshi R., Adhikari S., Patro BS, Chattadhyay S and Mukherjee T., (2001) free radical scavenging behavior of folic acid Evidence for possible antioxidant activity. Free Radic. Biol. Med,301390.

Kang SS, Wong PWK, Norusis M: Homocysteine due to folate deficiency.

Metabolism 36:458-462.

Kesavan V., Pote MS, Batra v and viswanthan G, (2003) increased folate catabolism total body irradiation in mice. J.Radiat Res, 44-141.

Kim Y.I., Salomon R. N., Graeme-Cook F., (1996): Dietary Folate protects against the development of macroscopic colonic neoplasia in a dose responsive manner in rats. Gut. (39): 732-740.

Metabolism 36: 458-462 1987.

LondheJS,DevasagayamTP,FooLY,Ghaskadbi SS.(2009). Radio- protective properties of polyphenols from Phyllanthusamarus Linn. J RadiatRes; 50:303-9.

Malinlinow MR. Hyperhomocyst (e) inenemia (2006): A common and easily reversible risk factor in occlusive atherosclerosis. Circulation 81.

Mason J. B., Choi s.W., (2000): Folate and carcinogenesis: developing a unifiying hypothesis. Adv. Enz. Regu. (40): 127141. 
McCully KS: Homocysteine theory of arteriosclerosis: Development and current status in Atherosclerosis reviews Vol 11, (ed.) By Gotto AM Jr., and Paoletti R, Raven Press NewYork, pp.157-246.

Nair C.K.K., and Menon A., (2013). Consumption of antioxidant dietry agents, Curcumin and Vitamin $\mathrm{C}$ protects cellular DNA from gamma radiation. Int. J. Radiat. Res,1:11-16.

Noronha JM,KesavanV,Viswanathan G: (1992). Antiatherogenic effect of folic acid in alcoholism Pteridines, 3: 143144.

Pancharuniti N, Lewis CA, Sauberlich HE, Perkins LL,GoRCP, Alvarez

JD, Maculo M: Action RT, Cooperland RB, Cousins AL, Gore TB, and Cornwell PE, (1994). Folate and carcinogenesis: developing a unifiying hypothesis. Adv. Enz. Regu. (91): 19-30.

Pote M. S., Gandhi N. M., and Mishra K. P., (2006). Antiatherogenic and radioprotective role of folic acid in whole body gamma irradiated
mice.Molecular and cellular Biochemistry (292): 19-25.

Sinclair AJ, Barnett AH, Lunec J. (1990): Free radicals and antioxidant systems in health and disease. Br J Hosp Med 43: $334-344$.

Yallapu M. M., Foy S. P., Jain T. K., Labhasetwaar V., (2010). PEGfunctionalized magnetic nanoparticles for drug delivery and magnetic resonance imaging applications. Pharm Res. (27): 2283-95.

Yehuda G., Rothem A. L., Hooijberg J. H., Stark M., Ifergan I., Kathmann I., Dijkmans B. A. C., Peters G. J., Jansen G., (2003): Loss of multidrug resistance protion 1 experession and folate efflux activity results in a highly concentrative folate transport in human leukemia cells. J. Biol. Chem. (278): 6680-6686.

Zhang J., Rana S., Sriavastava R. S., Misra R. D. K., (2008). On the chemical synthesis and drug delivery response of folate receptor- activated, polyethylene glycol- function-alized mabnetite nanoparticles. Acta Biomater (4). 40-8. 